\title{
Toxicity of ibuprofen and perfluorooctanoic acid for risk assessment of mixtures in aquatic and terrestrial environments
}

\author{
V. González-Naranjo • K. Boltes
}

Received: 18 December 2012/Revised: 29 April 2013/Accepted: 8 September 2013/Published online: 1 October 2013

(C) Islamic Azad University (IAU) 2013

\begin{abstract}
The toxicity of ibuprofen and perfluorooctanoic acid (PFOA) was evaluated individually and in binary combination on two photosynthetic organisms, the green alga Pseudokirchneriella subcapitata, representative of aquatic environments, and the monocotyledonous Sorghum bicolor, for terrestrial ecosystems. Both non-target organisms showed different sensitivities to pollutants. The alga was more affected than the plant to each compound assayed, whether separately or mixed in $\mathrm{EC}_{50}$ proportion, and PFOA was more toxic to both bioindicators. An analysis of toxic chemical interactions covering the whole range of effect levels was conducted using the Combination Index method and indicated that synergism could be expected at low effect levels in higher plants, while for algae this type of interaction predominated at higher effect levels. Ecological risk assessment was performed by calculating the Hazard Quotient as the ratio between the measured environmental concentration and the predicted no-effect concentration, using our $\mathrm{EC}_{50}$ data derived from the mixture of pollutants. Acute hazard was found in the terrestrial compartment (soil or sediments). In the light of the data reported, we conclude that risk evaluation should
\end{abstract}

Electronic supplementary material The online version of this article (doi:10.1007/s13762-013-0379-9) contains supplementary material, which is available to authorized users.

V. González-Naranjo · K. Boltes

Department of Chemical Engineering, University of Alcalá,

28771 Alcalá de Henares, Madrid, Spain

V. González-Naranjo $(\bowtie) \cdot$ K. Boltes

Madrid Institute of Advanced Studies in Water Technologies, IMDEAWater, Parque Científico Tecnológico, 28805 Alcalá de Henares, Madrid, Spain

e-mail: victor.naranjo@imdea.org include toxicological information on compound interactions that exert a toxic effect on non-target organisms.

Keywords Ibuprofen - Perfluorooctanoic acid . Pseudokirchneriella subcapitata · Risk assessment . Sorghum bicolor

\section{Introduction}

Ibuprofen (IBU) is a non-steroidal, anti-inflammatory, analgesic and antipyretic drug. It is an important non-prescription drug that is widely used. Its persistence, resistance to biodegradation and water solubility favour the entry of this drug into the environment, where it has been detected worldwide (Buchberger 2007; Martínez-Bueno et al. 2012; Behera et al. 2012). Perfluorooctanoic acid (PFOA) is a fluorinated organic chemical that belongs to the perfluorinated carboxylic acids. PFOA has widespread applications and is used as a processing aid (emulsifier) in the production of fluoropolymers and fluoroelastomers used as non-stick coating on cookware, membranes for waterproof/breathable clothing, electrical wire casing, fireand chemical-resistant tubing and plumbing thread seal tape. Concern about the occurrence of PFOA has increased due to its biotic and abiotic persistence, chronic toxicity, bioaccumulation and biomagnification (Lehmler 2005; Prevedouros et al. 2006).

The organic chemical removal efficiency of WWTPs is limited by secondary treatment processes, such as biological filters and activated sludge (Gómez et al. 2007). This contributes to significant pollution of receiving surface waters (Martínez-Bueno et al. 2012) or unsaturated zones in the case of wastewater reuse for agricultural irrigation (Kinney et al. 2006), which is widely regarded as a 
sustainable approach. Furthermore, since these contaminants are continuously introduced into the environment, they do not need to be persistent in order to have an effect on ecosystems (Petrović et al. 2003). Even at low concentrations, the occurrence of these emerging contaminants can lead to chronic adverse health effects, especially at highly contaminated sites and particularly when there is the possibility that organic compound mixtures may produce combined effects (Schnell et al. 2009). Studies on combined toxicity are very important because the organic pollutant residues found in environmental samples usually occur as mixtures, not as single contaminants, and the ecotoxicity values obtained for individual substances do not provide a safe rule for mixtures (Rodea-Palomares et al. 2010).

The toxicity effects of IBU and PFOA on aquatic organisms have been studied by measuring growth inhibition in green microalgae, such as Scenedesmus subspicatus and Pseudokirchneriella subcapitata (Cleuvers 2003; Yamamoto et al. 2007; Rosal et al. 2010). However, few studies have investigated their effects on plants (Zhao et al. 2011). To this end, Phytotoxkit, an ecotoxicity assay based on the direct contact method, can be used to measure the effects of pollutants on seed germination and root growth. This kind of test has been used to evaluate soils contaminated with different organic compounds (Sharifi et al. 2007; Sekutowski and Sadowski 2009; Banaszkiewicz et al. 2011; Martí et al. 2011). Sorghum bicolor is a member of the monocotyledonous Gramineae family and has been used as animal feed or as a soil fertiliser after composting with other wastes; however, nowadays it is mainly used for energy production by combustion (Monti and Venturi 2003). The possible harmful effect on crops caused by the occurrence of emerging contaminants such as IBU and PFOA has not been reported. However, risk assessment studies on pharmaceuticals and perfluorinated compounds in the environment require toxicological information derived from different trophic levels, especially on non-target organisms. Thus, most published data have been obtained from a limited set of organisms, such as bacteria, algae, invertebrates and fish (Yamamoto et al. 2007; Colombo et al. 2008).

The aim of this study was to evaluate the toxicity of IBU and PFOA towards two organisms, a higher plant (direct contact) and a green microalga (indirect contact). We also aimed to assess the toxicological effect of the mixture of both pollutants on the organisms in order to estimate ecological risk in aquatic and terrestrial environments due to the occurrence of these contaminants separately and in binary combination. This study was carried out in AprilJune of 2012 in the Toxicity Laboratory of the Department of Chemical Engineering of University of Alcala and Water Analysis Laboratory of IMDEA-Water (Madrid).

\section{Materials and methods}

Soil samples

Four different soils were used in the experiments (A, B, C and D). All of them were surface soil samples $(0-30 \mathrm{~cm})$, collected at Carrión de los Céspedes, Seville, Spain. Soils were air-dried and passed through a 2-mm sieve before conducting the batch experiments. A fifth soil sample, soil E, was obtained by pooling the four samples. Particle size distribution was analysed following the Bouyoucos method. Soil pH and electrical conductivity (EC) were measured in a soil-water suspension (1:2.5 and 1:5 soilwater ratio, respectively). Percentage of calcium carbonate $\left(\mathrm{CaCO}_{3}\right)$ equivalent was measured using a Bernard calcimeter. Organic matter $(\mathrm{OM})$ was determined by means of the potassium dichromate-sulphuric acid method.

\section{Chemicals}

Ibuprofen sodium salt $\left(\mathrm{C}_{13} \mathrm{H}_{17} \mathrm{NaO}_{2}\right.$, CAS No. 31121-93-4, $98 \%$ ) and perfluorooctanoic acid (PFOA, $\mathrm{C}_{8} \mathrm{HF}_{15} \mathrm{O}_{2}$, CAS No. 335-67-1, 99.2\%) were purchased from SigmaAldrich (Spain).

\section{Toxicity bioassays}

The algal test was conducted according to OECD TG 201 (OECD 2008), as reported by Boltes et al. (2012). The green alga $P$. subcapitata was selected to be representative of aquatic environments. Organisation for Economic Co-operation and Development (OECD) has standardised tests that measure toxicity of dissolved chemicals as inhibition of growth over 3-4 days in replicate microalgal cultures, typically using model test species, such as P. subcapitata (OECD 1984). It is commonly used for aquatic toxicological testing because they are easy to grow and expose to dissolved toxins in culture, they are sensitive to hazardous chemicals or wastewater contaminants and they have short generation times that allow rapid assessment of growth responses to toxins. The test was performed in aqueous 1:10 soil eluate (composition shown in Table S1, supplementary information) enriched with a concentrated algal culture medium. Stock solutions of IBU and PFOA were prepared in phosphate buffer solution at $\mathrm{pH}=7$.

Terrestrial plant toxicity assays were performed according to OECD TG 208 (OECD 2003), using Phytotoxkit (Microbiotest, Belgium) to evaluate inhibition of seed germination and root elongation in S. bicolor. This high plant was selected due to their properties such as the uniformity of the seeds (they are readily available from standard sources, which produce them consistently), the 
uniformity of the seedling growth and the amenability to testing in the laboratory, giving reliable and reproducible results. For these reasons, the $S$. bicolor is included in the list of the OECD guideline for the testing of chemicals in terrestrial plants (OECD 2003). Besides, it is a crop that is commonly irrigated with reclaimed water. Three control runs were also included, consisting of soil without contaminants. After 3-day incubation, a digital picture was taken of the germinated plants. Analysis and length measurements were taken using the Image Tool 3.0 for Windows (UTHSCSA, San Antonio, USA). The percentage inhibition of seed germination (SI) and root elongation (RI) for each plant was calculated using the following formula:

$\mathrm{SI} / \mathrm{RI}=\frac{A-B}{A} \cdot 100$

where $A$ is the mean seed germination/root elongation in the control soil and $B$ is the mean seed germination/root elongation in the test soil.

For both bioassays, serial dilutions of each compound, individually and with a fixed constant ratio (1:1) based on their individual $\mathrm{EC}_{50}$ values, were prepared using a dilution factor of 2 for the mixture of IBU and PFOA.

Stability of exposure concentration

In accordance with the OECD Guideline for Testing Chemicals (OCDE 2008), evaluation of photosensitive pollutant stability and biodegradability under chronic test conditions was performed at the start and at the end of the exposure period. To this end, a 1:10 soil solution in deionised water was prepared, and chemicals plus nutrients were added from their stock solutions to reach initial concentrations corresponding to the $\mathrm{EC}_{50}$ values of PFOA and IBU separately. After 3-day incubation with and without algal biomass, HPLC-UV analyses were conducted of initial and final liquid samples. IBU analysis was carried out using HPLC-UV (1200-Series, Agilent technologies) equipped with a Phenomenex C-18 column $(15 \mathrm{~cm} \times 4.60 \mathrm{~mm}, 5 \mu \mathrm{m})$ and $2 \mathrm{~mL} / \mathrm{min}$ of $37: 63$ acetonitrile/water (pH 2.5 adjusted by orthophosphoric acid). PFOA was measured using the same equipment and elution at $1 \mathrm{~mL} / \mathrm{min}$ using 60:40 acetonitrile/water (with $10 \mathrm{mM}$ of ammonium acetate at $\mathrm{pH} 3$ ). Detection was performed at $210 \mathrm{~nm}$ for both compounds.

\section{Calculation of dose-response parameters}

The response of both organisms to toxic exposure was evaluated using the median-effect equation based on the mass-action law as described by Chou and Talalay (1984) and reported previously by Boltes et al. (2012):
$\frac{f_{a}}{1-f_{a}}=\left(\frac{D}{\mathrm{EC}_{50}}\right)^{m}$

where $f_{a}$ represents the fraction of the population affected by a certain dose, $D$, expressed as a concentration of toxicant. $\mathrm{EC}_{50}$ (potency) and $m$ (shape) values of both compounds and their mixture were determined. $\mathrm{EC}_{50}$ is the concentration required to detect a negative effect of $50 \%$ through a selected endpoint for each organism (inhibition of growth for the alga and inhibition of seed germination or root elongation for the plant). The Combination Index (CI) was also determined for all effect levels, according to the general CI equation (Chou 2006):

${ }^{n}(C I)_{x}=\sum_{j=1}^{n}\left[D_{j} /\left(D_{x}\right)_{j}\right]=\sum_{j=1}^{n} \frac{\left(D_{x}\right)_{1-n}\left[\frac{[D]_{j}}{\sum_{1}^{n}[D]}\right]}{\left(D_{m}\right)_{j}\left[\frac{\left(f_{a x}\right)_{j}}{1-\left(f_{a x}\right)_{j}}\right]^{\frac{1}{m_{j}}}}$

where ${ }^{n}(\mathrm{CI})_{x}$ is the CI for $n$ chemicals at $x \%$ effect, $\left(D_{x}\right)_{1-n}$ is the sum of the dose of $n$ chemicals that exerts $x \%$ inhibition in combination, $\left[D_{j}\right] / \sum_{1}^{n}[D]$ is the proportion of the dose of each chemical that exerts $x \%$ inhibition in combination and $\left(D_{\mathrm{m}}\right)_{\mathrm{j}}\left\{\left(f_{a x}\right)_{\mathrm{j}}\left[\left[1-\left(f_{a x}\right)_{j}\right]\right\}^{1 / m j}\right.$ is the dose of each compound alone that exerts $x \%$ inhibition. Calculation of $\mathrm{EC}_{50}, m$, CI as well as $\mathrm{EC}_{10}, \mathrm{EC}_{20}$ and $\mathrm{EC}_{90}$ values was performed using the software CompuSyn (Chou and Martin 2005).

Hazard quotient assessment

The actual potential ecological risk of a pollutant can be estimated through calculation of an index known as HQ. This is defined as the ratio between predicted environmental concentrations (PECs) or measured environmental concentrations (MECs) and predicted no-effect concentrations (PNECs) (Sanderson et al. 2003; Von der Ohe et al. 2011), according to Eq. 4.

$\mathrm{HQ}=\mathrm{MEC} / \mathrm{PNEC}$

For individual pollutants, MEC values were obtained from the literature, but for the binary mixture studied, this value was calculated from the sum of maximum concentrations detected in each scenario (water for alga and soil or sediment for plant). PNEC values were derived by dividing the $\mathrm{EC}_{50}$ values obtained in this study by an assessment factor of 1,000 (Sanderson et al. 2003; EMEA 2006; Von der Ohe et al. 2011).

\section{Results and discussion}

Physical and chemical properties of the soils

The physical and chemical properties of the four soils used in the experiments are listed in Table S2 (supplementary 
information). The samples were slightly alkaline (A and B) or moderately alkaline (C, D and E). Both salinity (EC values were between 0.14 and $0.24 \mathrm{dS} / \mathrm{m}$ ) and calcium carbonate (the percentage ranged from 0.13 to $0.27 \%$ ) were low. The soils presented medium OM content, with the minimum value of $1.76 \%$ for soil $A$ and a maximum of $3.51 \%$ for soil $B$. As regards texture, all the soils were loam, except soil A, which was clay-loam.

\section{Toxicity of individual compounds}

Table 1 shows the dose-effect curve parameters for IBU and PFOA in both organisms, expressed as $\mathrm{EC}_{10}, \mathrm{EC}_{20}$, $\mathrm{EC}_{50}$ and $\mathrm{EC}_{90}$ values $(\mathrm{mg} / \mathrm{L})$ with $95 \%$ confidence interval, which was determined using a linear interpolation method independent of any particular dose-effect model (USEPA 2002).

In Table 1 it can be seen that $r$ values were $>0.98$ in all cases, indicating a good linear correlation of the medianeffect plots. According to the $\mathrm{EC}_{50}$ value, IBU could be classified as not harmful to algae according to the criteria of Regulation (EC) No. 1272/2008. In their study on P. subcapitata, Yamamoto et al. (2007) obtained $\mathrm{EC}_{50}$ values for IBU of $360 \mathrm{mg} / \mathrm{L}$, higher than those reported here. Similarly, Cleuvers (2004) obtained an $\mathrm{EC}_{50}$ of $342.2 \mathrm{mg} / \mathrm{L}$ for the green alga $S$. subspicatus. We observed a significant and measurable negative effect above $35 \mathrm{mg} / \mathrm{L}$ of IBU, higher than the value reported by Yamamoto (2007) and similar to that obtained by Cleuvers (2004), whose data were 32 and $2 \mathrm{mg} / \mathrm{L}$, respectively. Unlike the present study, neither of these previous studies used soil eluate to culture algae; however, comparison of the growth rate of $P$. subcapitata in standard OECD medium did not show significant differences in the measured rate of cell growth in the soil solution including nutrients.

Using the same criteria, PFOA can be classified as harmful for algae, with an $\mathrm{EC}_{50}$ that was very similar to that reported by Rosal et al. (2010), of $96.2 \mathrm{mg} / \mathrm{L}$. EC 10 and $\mathrm{EC}_{20}$ values were not found in the literature for aquatic organisms. Algal growth was only affected by this pollutant at concentrations above $10 \mathrm{mg} / \mathrm{L}$ in the soil eluate solution.

Plant root elongation was significantly inhibited by IBU and PFOA additions to the soil. The $\mathrm{EC}_{50}$ values showed that neither IBU nor PFOA could be classified as not harmful to S. bicolor. Li (2009) found lower toxicity of PFOA towards lettuce, pak choi and cucumber, with $\mathrm{EC}_{50}$ values of 170, 278 and $1254 \mathrm{mg} / \mathrm{L}$, respectively. Results similar to ours were reported by Zhao et al. (2011), where they evaluated inhibition of root elongation in Brassica chinensis due to PFOA addition to soils with different physical and chemical characteristics. These authors obtained $\mathrm{EC}_{50}$ values that ranged from 107 to $246 \mathrm{mg} / \mathrm{kg}$

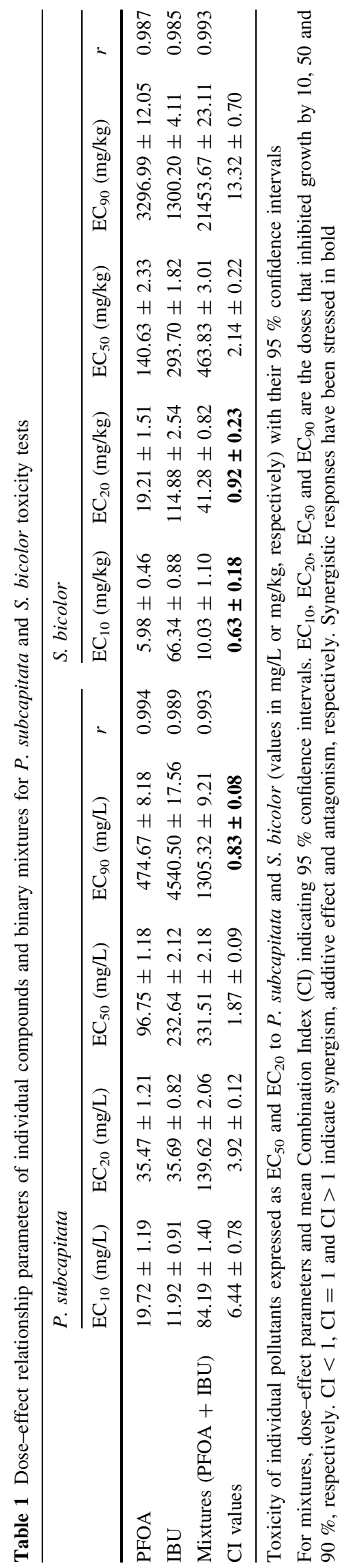


and observed that toxicity was highly dependent on the $\mathrm{OM}$ content of soils used. Differences in the toxicity values observed may be explained by the dissimilar nature of the organisms studied. Given that organism-chemical interactions involve two processes, uptake (bioavailability) and toxicokinetics, which refers to transport within organism to the receptors (Katayama et al. 2010), the physical and chemical characteristics of the soil could also be expected to affect the effective exposure concentration in plant toxicity assays, but not in algal tests, since the pollutants were added to a soil solution prepared prior to the exposure period. A reduction in bioavailability probably occurs in plant assays, mainly due to the sorption of pollutants by organic and inorganic soil fractions, as was extensively discussed by Katayama et al. (2010). In our soil was expected a moderate sorption effect due to the clay and the OM contents, of 20 and $2.26 \%$, respectively. In fact, Zhao et al. (2011) obtained a good positive correlation between PFOA toxicity data and OM content of soils, and they concluded that this is the most important parameter controlling phytotoxicity in higher plants. Given that both the compounds used here have high $\mathrm{K}_{\mathrm{OW}}$ values ( 3.97 for IBU and 6.44 for PFOA), their affinity for the soil organic fraction could be assumed to be similar and the bioavailability of these pollutants to the Gramineae can also be considered similar.

In this study, nominal concentrations of the chemicals were used for dose-effect parameter calculations, since biodegradation of both pollutants in the environment has been proven to be insignificant (Moriwaki et al. 2005; Lin and Gan 2011). In addition, we tested degradation at $22{ }^{\circ} \mathrm{C}$ under light irradiation in soil eluate, observing only small differences between initial and final concentrations of both compounds ( $<10 \%$ for IBU and $<5 \%$ for PFOA). These values confirmed that IBU and PFOA are resistant to transformation by the action of light or by the microflora extracted from soil by elution.

\section{Toxicity of mixtures}

The results for the binary mixture are also shown in Table 1. The dose-effect curve parameters were determined from Eq. 2 (Chou 2006): $\mathrm{EC}_{50}, m$ and $r$ (linear correlation coefficient corresponding to the data in logarithmic form). The mean CI was obtained from Eq. 3 and appeared with $95 \%$ confidence intervals for $\mathrm{EC}_{10}, \mathrm{EC}_{20}$, $\mathrm{EC}_{50}$ and $\mathrm{EC}_{90}$ values, which were the doses that inhibited growth by $10,20,50$ and $90 \%$, respectively. As with exposure to single toxicants, the correlation coefficient, $r>0.99$, indicates that the data for binary mixtures have a good fit with the median-effect principle in both organisms.

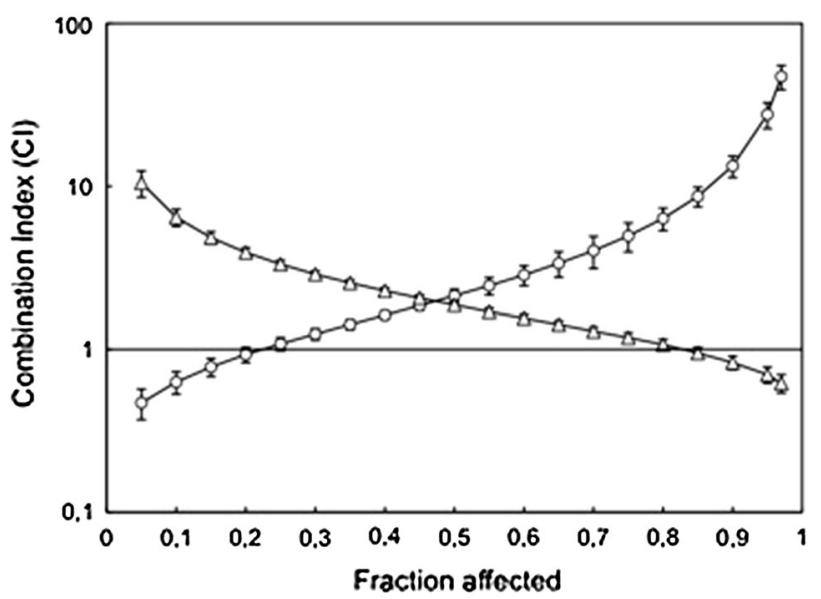

Fig. 1 Combination Index plot for mixtures of ibuprofen and PFOA obtained for the algal test (triangles) and for the plant test (circles). The line at $\mathrm{CI}=1$ represents additivity

According to the results for the plant, the presence of PFOA reduced the toxicity effect of IBU in a soil environment. Fig. 1 shows the evolution of CI values with the population fraction affected. It can be observed in this figure that CI varied widely from lowest to highest effect levels in both the ecotoxicity tests performed.

The effect on S. bicolor was synergic at lower $f_{a}$ levels. This tendency changed at $f_{a}=0.25$, and a very strong antagonist effect was observed at the highest level. In previous studies by Bakopoulou et al. (2011) and Oleszczuk and Hollert (2011), seed germination proved to be a weaker indicator of phytotoxicity than root growth. In our study, we did not find a relationship between concentration level and inhibition, and a non-significant effect was observed in the assay. Hence, determination of $\mathrm{EC}_{50}$ for this endpoint was not possible.

The $\mathrm{EC}_{50}$ for P. subcapitata increased when both pollutants were mixed in a constant ratio based on their individual $\mathrm{EC}_{50}$ proportion. Therefore, even when these two contaminants were mixed, the alga was more affected than the plant. For the alga, the interaction was antagonistic at lower $f_{a}$ levels, changing at $f_{a}=0.8$, until reaching the highest $f_{a}$ level, where synergism was observed. In our previous study (Boltes et al. 2012), we reported that a binary combination of perfluorooctane sulphonic acid (PFOS) and a fibrate (gemfibrozil or bezafibrate) always exhibited an antagonistic effect on $P$. subcapitata growth in all the affected fractions, but the pattern of variation was opposite for each binary combination. Rodea-Palomares et al. (2012) also studied the interaction between mixtures of PFOA and other pharmaceuticals on a recombinant bioluminescent cyanobacterium. They obtained similar results for the binary combination of PFOA plus the antibiotic furazolidone or mitomycin $\mathrm{C}$, where an antagonistic effect was 
observed for the whole range of $f_{a}$ for furazolidone + PFOA. For mitomycin + PFOA, the authors observed a slightly antagonistic effect only above an $f_{a}$ value of 0.7 .

For IBU, no combinations with perfluorinated chemicals were found in the literature, but cumulative effects have been reported when combined with other pharmaceuticals, such as diclofenac (Cleuvers 2003).

Regarding the differences in toxicological profiles obtained for the binary mixtures, these are difficult to discuss due to the limited information available about the combined action of chemicals and the unknown mechanisms of action of these compounds on non-target organisms. In the previous studies, we found that the same combination of toxicants could result in totally different toxicity effects on aquatic organisms when compared to effects on bacteria, cyanobacteria and green algae. In addition, the type and degree of interaction may differ according to the affected population fraction (Rodea-Palomares et al. 2010; Rosal et al. 2010). In this study, the binary combination involved a decreased toxic effect on both organisms, according to the antagonism found around the $\mathrm{EC}_{50}$ values, but showed different toxicity patterns over the entire range of effect levels. These results highlight the importance of deriving toxicity data for mixtures of important contaminants at different trophic levels in order to carry out a more rigorous risk assessment.

\section{Hazard quotient assessment}

The lowest PNECs for individual pollutants and the binary mixture were obtained from the $\mathrm{EC}_{50}$ values calculated in this study for each organism, as indicated in Sect. 2.6. This information was combined with the available MECs found in the literature for both pollutants in surface waters, wastewater effluents, soil and river sediments, which are shown in Table S3 (supplementary information). Table 2 summarises the MEC, PNEC and HQ values estimated for single and combined pollutants on both organisms.

In order to evaluate the potential risk to water and soil environments, the maximum measured concentration of each pollutant was used for each scenario, and MEC values for binary mixtures were obtained from the sum of highest individual occurrences. HQ $<0.1$ indicates that no adverse effect is expected for the organism evaluated in its environment; if $0.1<\mathrm{HQ}<1$, a potentially adverse effect should be considered, but at $1<\mathrm{HQ}<10$, a moderate hazard must be expected. Additionally, HQ $>10$ indicates that a high risk is probable (EMEA 2006).

HQ values above 1 are indicated in bold in Table 2. As can be seen, values for both compounds separately were above this threshold value of 1 in S. bicolor, compared to $P$. subcapitata, for which no potential risk was detected to aquatic environments due to the occurrence of each compound either separately or combined. The IBU + PFOA mixture presented an ecological risk to soil environments similar to the risk associated with IBU, but in binary combination, the risk associated with the occurrence of PFOA in soil environments was lowered, in accordance with the antagonistic effect shown at high effect level (Fig. 1). A simple cumulative approach to HQs for the compound could result in an overestimation of risk to wastewater $(\mathrm{HQ}=0.59)$, soil $(\mathrm{HQ}=3.36)$ and sediments $(\mathrm{HQ}=1.56)$, emphasising the importance of risk evaluation based on toxicological information on the mixture of pollutants. According to our results, acute hazard could be expected in soils due principally to the greater damage caused by PFOA in plants at lower concentration levels than those reported in the literature for this compartment.

Despite the high level of scientific activity in the field of water quality, from which most HQ values were obtained, no studies have reported HQ values for pollutant mixtures derived from experimental toxicity data, such as those obtained in our study. Only a few previous studies have been published which assessed ecotoxicological risk due to the combined occurrence of pollutants. In the study by Valcárcel et al. (2011), cumulative HQs were obtained for several pharmaceuticals at different sampling points along rivers and in drinking water supply areas in the Madrid region (Spain). The aim was to estimate the potential risk at sites where multiple pharmaceuticals occurred

Table 2 Lowest predicted no-effect concentrations (PNECs) and measured environmental concentrations (MECs) used for the calculation of Hazard Quotients (HQs) of individual compound and binary mixtures in water and soil environments

\begin{tabular}{|c|c|c|c|c|c|c|c|c|c|c|}
\hline \multirow[t]{2}{*}{ Compound } & \multicolumn{5}{|c|}{ P. subcapitata } & \multicolumn{5}{|l|}{ S. bicolor } \\
\hline & $\begin{array}{l}\text { MEC }(\mu \mathrm{M}) \\
\text { surface } \\
\text { water }\end{array}$ & $\begin{array}{l}\text { MEC }(\mu \mathrm{M}) \\
\text { wastewater }\end{array}$ & $\begin{array}{l}\text { PNEC } \\
(\mu \mathrm{M})\end{array}$ & $\begin{array}{l}\text { HQ surface } \\
\text { water }\end{array}$ & $\begin{array}{l}\text { HQ } \\
\text { wastewater }\end{array}$ & $\begin{array}{l}\text { MEC } \\
(\mu \mathrm{mol} / \mathrm{kg}) \\
\text { soil }\end{array}$ & $\begin{array}{l}\text { MEC } \\
(\mu \mathrm{mol} / \mathrm{kg}) \\
\text { sediments }\end{array}$ & $\begin{array}{l}\text { PNEC } \\
(\mu \mathrm{mol} / \mathrm{kg})\end{array}$ & $\begin{array}{l}\mathrm{HQ} \\
\text { soil }\end{array}$ & $\begin{array}{l}\mathrm{HQ} \\
\text { sediments }\end{array}$ \\
\hline Ibuprofen (IBU) & 0.368 & 0.267 & 1.128 & 0.239 & 0.173 & 1.544 & 0.174 & 1.424 & 1.084 & 0.122 \\
\hline PFOA & 0.082 & 0.010 & 0.234 & 0.351 & 0.045 & 0.773 & 0.490 & 0.340 & 2.276 & 1.443 \\
\hline $\mathrm{IBU}+\mathrm{PFOA}$ & 0.450 & 0.277 & 1.286 & 0.350 & 0.215 & 2.317 & 0.664 & 1.719 & 1.348 & 0.386 \\
\hline
\end{tabular}


simultaneously, but ecotoxicity data for each individual chemical were taken from the literature or, if unavailable, estimated using (Q)SAR models. Similarly, Yamamoto et al. (2011) applied two cumulative risk evaluation approaches to estimate the risk due to the occurrence of seven parabens in water, but their hazard evaluation was based on toxicity data obtained for each compound individually, and did not include any synergistic or antagonist effects. Although both these previous studies employed a different methodology, the idea was the same, to estimate the HQ in a real situation where an organism is exposed to a mixture of pollutants instead of to a single compound. Similarly, the same problem was encountered: the lack of information on combined toxicity effects on the exposed organism studied, highlighting the pressing need for ecotoxicity data on mixtures of environmentally important pollutants. Our results can help to rectify this problem, since risk evaluation could be performed using the experimental dose-effect parameters obtained for mixtures, independently of the number of components or the type of organism studied.

\section{Conclusion}

We have reported individual and combined ecotoxicity data for the effect of two important pollutants, IBU and PFOA, on two photosynthetic organisms: a green microalga and a higher plant. Our results show that $P$. subcapitata is more sensitive than S. bicolor to each chemical individually as well as to the binary combination and that PFOA was more damaging than IBU for both organisms. The toxicological interaction profiles obtained changed in each toxicity test. For the plant, we estimated synergisms at lower effect levels, while for the alga, antagonism was the most probable toxicological interaction expected at the same effect level. In addition, we have presented a method for conducting risk assessment through HQ calculation, based on experimental dose-effect parameters obtained for mixtures. This method can be used for multicomponent mixtures of pollutants and with any kind of organism, independently of the mode of action of the toxicants.

Acknowledgments This research was funded by the next research projects: MICINN-CGL2009-13168-C03-01, CSD2006-00044, P2009/AMB-1588 and CCG10-UAH/AMB-5899.

\section{References}

Bakopoulou S, Emmanouil C, Kungolos A (2011) Assessment of wastewater effluent quality in Thessaly region, Greece, for determining its irrigation reuse potential. Ecotoxicol Environ Saf 74:188-194

Banaszkiewicz T, Szarek J, Wysocki K (2011) Biological evaluation of soil contamination around a non-operating pesticide tomb. Pol J Environ Stud 20:485-488

Behera SK, Oh SY, Park HS (2012) Sorptive removal of ibuprofen from water using selected soil minerals and activated carbon. Int J Environ Sci Tech 9(1):85-94

Boltes K, Rosal R, García-Calvo E (2012) Toxicity of mixtures of perfluorooctane sulphonic acid with chlorinated chemicals and lipid regulators. Chemosphere 86:24-29

Buchberger WW (2007) Novel analytical procedures for screening of drug residues in water, wastewater, sediment and sludge. Anal Chim Acta 593:129-139

Chou TC (2006) Theoretical basis, experimental design, and computerized simulation of synergism and antagonism in drug combination studies. Pharmacol Rev 58:621-681

Chou TC, Martin N (2005) CompuSyn for drug combinations: PC software and user's guide: a computer program for quantification of synergism and antagonism in drug combinations and the determination of $\mathrm{IC}_{50}$ and $\mathrm{ED}_{50}$ and $\mathrm{LD}_{50}$ values. ComboSyn, Inc., Paramus

Chou TC, Talalay P (1984) Quantitative analysis of dose-effect relationships: the combined effects of multiple drugs or enzyme inhibitors. Adv Enzyme Regul 22:27-55

Cleuvers M (2003) Aquatic ecotoxicity of pharmaceuticals including the assessment of combination effects. Toxicol Lett 142:185-194

Cleuvers M (2004) Mixture toxicity of the anti-inflammatory drugs diclofenac, ibuprofen, naproxen, and acetylsalicylic acid. Ecotoxicol Environ Saf 59:309-315

Colombo I, de Wolf W, Thompson RS, Farrar DG, Hoke RA, L'Hariden J (2008) Acute and chronic aquatic toxicity of ammonium perfluorooctanoate (APFO) to freshwater organisms. Ecotoxicol Environ Saf 71:749-756

EMEA (2006) European Chemical Agency. Guideline on the Environmental Risk Assessment of Medicinal products for human use. Doc ref. EMEA/CHMP/SWP/4447/00

Gómez MJ, Martínez-Bueno MJ, Lacorte S, Fernández-Alba AR, Agüera A (2007) Pilot survey monitoring pharmaceuticals and related compounds in a sewage treatment plant located on the Mediterranean coast. Chemosphere 66:993-1002

Katayama A, Bhula R, Burns GR, Carazo E, Felsot A, Hamilton D, Harris C, Kim YH, Kleter G, Koerdel W, Linders J, Peijnenburg JGMW, Sabljic A, Stephenson RG, Racke DK, Rubin B, Tanaka K, Unsworth J, Wauchope RD (2010) Bioavailability of xenobiotics in the soil environment. Rev Environ Contam Toxicol 203:1-86

Kinney CA, Furlong ET, Werner SL, Cahill ID (2006) Presence and distribution of wastewater-derived pharmaceuticals in soil irrigated with reclaimed water. Environ Toxicol Chem 25:317-326

Lehmler HJ (2005) Synthesis of environmentally relevant fluorinated surfactants-a review. Chemosphere 58:1471-1496

Li MH (2009) Toxicity of perfluorooctane sulfonate and perfluorooctanoic acid to plants and aquatic invertebrates. Environ Toxicol 24:95-101

Lin K, Gan J (2011) Sorption degradation of wastewater-associated non-steroidal anti-inflammatory drugs and antibiotics in soils. Chemosphere 83:240-246

Martí E, Sierra J, Cáliz J, Montserrat G, Vila X, Garau MA, Cruañas R (2011) Ecotoxicity of chlorophenolic compounds depending on soil characteristics. Sci Total Environ 409:2707-2716

Martínez-Bueno MJ, Gómez MJ, Herrera S, Hernando MD, Agüera A, Fernández-Alba AR (2012) Occurrence and persistence of organic emerging contaminants and priority pollutants in five 
sewage treatment plants of Spain: two years pilot Survey monitoring. Environ Pollut 164:267-273

Monti A, Venturi G (2003) Comparison of the energy performance of fibre sorghum, sweet sorghum and wheat monocultures in northern Italy. Eur J Agron 19:35-43

Moriwaki H, Takagi Y, Tanaka M, Tsuruho K, Okitsu K, Maeda Y (2005) Sonochemical decomposition of perfluorooctane sulfonate and perfluorooctanoic acid. Environ Sci Technol 39:3388-3392

OECD (1984) Guidelines for Testing of Chemicals, Number 201: Alga, Growth Inhibition Test

OECD (2003) Guidelines for the Testing of Chemicals. Proposal for updating guideline 208. Terrestrial plant test: 208. Seedling emergence and seedling growth test; 2003. Draft Document

OECD (2008) Guidelines for the Testing of Chemicals, No. 23: Guidance Document on Aquatic Toxicity Testing of Difficult Substances and Mixtures, PDF Edition (ISSN 1607-310X), 18th Addendum

Oleszczuk P, Hollert H (2011) Comparison of sewage sludge toxicity to plants and invertebrates in three different soils. Chemosphere 83:502-509

Petrović M, Gonzalez S, Barcelo D (2003) Analysis and removal of emerging contaminants in wastewater and drinking water. TracTrend Anal Chem 22:685-696

Prevedouros K, Cousins IT, Buck RC, Korzeniowski SH (2006) Sources, fate and transport of perfluorocarboxylates. Environ Sci Technol 40:32-44

REGULATION (EC) No 1272/2008 OF THE EUROPEAN PARLIAMENT AND OF THE COUNCIL of 16 December 2008 on classification, labelling and packaging of substances and mixtures, amending and repealing. Directives 67/548/EEC and 1999/45/EC, and amending Regulation (EC) No 1907/2006

Rodea-Palomares I, Petre AL, Boltes K, Leganés F, Perdigón-Melón JA, Rosal R, Fernández-Piñas F (2010) Application of the combination index (CI)-isobologram equation to study the toxicological interactions of lipid regulators in two aquatic bioluminescent organisms. Water Res 44:427-438

Rodea-Palomares I, Leganés F, Rosal R, Fernández-Piñas F (2012) Toxicological interactions of perfluorooctane sulfonic acid (PFOS) and perfluorooctanoic acid (PFOA) with selected pollutants. J Hazard Mater 201-202:209-218

Rosal R, Rodea-Palomares I, Boltes K, Fernández-Piñas F, Leganés F, Petre A (2010) Ecotoxicological assessment of surfactants in the aquatic environment: combined toxicity of docusate with chlorinated pollutants. Chemosphere 81:288-293

Sanderson H, Johnson DJ, Wilson CJ, Brain RA, Solomon KR (2003) Probabilistic hazard assessment of environmentally occurring pharmaceuticals toxicity to fish, daphnids and algae by ECOSAR screening. Toxicol Lett 144:383-395

Schnell S, Bols NC, Barata C, Porte C (2009) Single and combined toxicity of pharmaceuticals and personal care products (PPCPs) on the rainbow trout liver cell line RTL-W1. Aquat Toxicol 93:244-252

Sekutowski T, Sadowski J (2009) Phytotoxkit (tm) microbiotest used in detecting herbicide residue in soil. Environ Prot Eng $35: 105-110$

Sharifi M, Sadeghi Y, Akbarpour M (2007) Germination and growth of six plant species on contaminated soil with spent oil. Int J Environ Sci Tech 4:463-470

USEPA (2002) Methods for measuring the acute toxicity of effluents and receiving waters to freshwater and marine organisms, 5th Edition. US Environmental Protection Agency, Washington DC EPA-812-R02-012

Valcárcel Y, González Alonso S, Rodríguez-Gil JL, Gil A, Catalá M (2011) Detection of pharmaceutically active compounds in the rivers and tap water of the Madrid Region (Spain) and potential ecotoxicological risk. Chemosphere 84:1336-1348

Von der Ohe PC, Dulio V, Slobodnik J, De Deckere E, Kühne R, Ebert RU, Ginebreda A, De Cooman W, Schürmann G, Brack W (2011) A new risk assessment approach for the prioritization of 500 classical and emerging organic microcontaminants as potential river basin specific pollutants under the European Water Framework Directive. Sci Total Environ 409:2064-2077

Yamamoto H, Nakamura Y, Nakamuri Y, Kitani C, Imari T, Sekizawa J, Takao Y, Yamashita N, Hirai N, Oda S, Tatarazako N (2007) Initial ecological risk assessment of eight selected human pharmaceuticals in Japan. Environ Sci 14:177-193

Yamamoto H, Tamura I, Hirata Y, Kato J, Kagota K, Katsuki S, Yamamoto A, Kagami Y, Tatarazako N (2011) Aquatic toxicity and ecological risk assessment of seven parabens: individual and additive approach. Sci Total Environ 410-411:102-111

Zhao H, Chen C, Zhang X, Chen J, Quan X (2011) Phytotoxicity of PFOS and PFOA to Brassica chinensis in different Chinese soils. Ecotox Environ Safe 74:1343-1347 